\title{
Aproximación al proceso de estigmatización social de las personas mayores LGBT en Antioquia, Colombia
}

\section{Approach to the process of social stigmatization of LGBT seniors in Antioquia, Colombia}

\author{
Jair Eduardo Restrepo-Pineda, Andrea Carolina López-Lorduy \\ y Alejandro Arismendy-Mejía
}

Corporación Universitaria Minuto de Dios UNIMINUTO, Colombia

\section{Resumen}

El objetivo del artículo fue realizar una aproximación a los estigmas que se tejen alrededor de las personas mayores LGBT, para lo cual se diseñó una investigación cualitativa con un enfoque hermenéutico-interpretativo, utilizándose una muestra por conveniencia, en la cual participaron diez personas mayores LGBT, de los cuales siete fueron gais, dos lesbianas y una mujer transgénero. Los hallazgos permitieron identificar tres estereotipos, el primero es suponer a estos adultos como personas asexuadas; el segundo pensar que están condenados a la soledad por su orientación sexual o identidad de género, y finalmente, un tercero referido a la salida del armario, donde se piensa que estas personas no asumen su sexualidad de manera abierta y empoderada. En consecuencia, estos estigmas y estereotipos conducen a la invisibilización social del adulto mayor LGBT lo que finalmente influye en su mayor vulnerabilidad y riesgo de exclusión y marginación social.

Palabras clave: Vejez, envejecimiento, minorías sexuales, estigma.

Abstract

The objective of the article was to make an approach to the stigmas that are woven around LGBT older adults, for which a qualitative research was designed with a hermeneutical-interpretive approach, using a convenience sample, in which ten LGBT older adults participated, of which seven were gay, two were lesbians and one was transgender. The findings made it possible to identify three stereotypes, the first is to assume these adults as asexual people; the second to think that they are condemned to loneliness because of their sexual orientation or gender identity, and finally, a third refers to coming out of the closet, where it is thought that these people do not accept their sexuality in an open and empowered way. Consequently, these stigmas and stereotypes lead to the social invisibility of the LGBT older adult, which ultimately influences their greater vulnerability and risk of social exclusion and marginalization.

Keywords: Old age, oging, sexual minorities, stigma. 


\section{INTRODUCCIÓN}

$\mathbf{L}$

a vejez constituye un proceso heterogéneo a lo largo del cual se acumulan, entre otros, necesidades, limitaciones, cambios, pérdidas, capacidades, oportunidades y fortalezas humanas, donde se encuentra presente el envejecimiento humano, entendido como un proceso multidimensional de los seres humanos que se caracteriza por ser heterogéneo, intrínseco e irreversible; inicia en la concepción, se desarrolla durante el curso de vida y termina con la muerte. Es un proceso complejo e incluye cambios biológicos y psicológicos de los individuos en interacción continua con la vida social, económica, cultural y ecológica de las comunidades, durante el transcurso del tiempo (Ministerio de Salud y Protección Social de Colombia, 2014).

Teniendo en cuenta estos el Ministerio de Salud y Protección Social de Colombia puntualiza que

las personas adultas mayores son sujetos de derecho, socialmente activos, con garantías y responsabilidades respecto de sí mismas, su familia y su sociedad, con su entorno inmediato y con las futuras generaciones. Las personas envejecen de múltiples maneras dependiendo de las experiencias, eventos cruciales y transiciones afrontadas durante sus cursos de vida, es decir, implica procesos de desarrollo y de deterioro. Generalmente, una persona adulta mayor es una persona de 60 años o más de edad (2014: 1).

En consecuencia, se puede afirmar que no existe una sola forma de vejez, sino que se presentan variadas formas de llegar a esta etapa del ciclo vital, las cuales están determinadas por las trayectorias de vida de las personas, sus redes de apoyo social y familiar, y la acumulación de capacitación social y cultural a lo largo de sus vidas. Esta situación se evidencia de manera precisa en las personas mayores LGBT que fueron entrevistados en el desarrollo de este estudio, ya que sus trayectorias de vida están marcadas por una doble discriminación, por un lado, aquella relacionada con la edad y, de otra parte, la referida a su orientación sexual e identidad de género, entendiendo la orientación sexual como "la dirección del deseo erótico y la afectividad de las personas en razón al sexo o identidad de género de las otras personas" (Consejería de Derechos Humanos de la Presidencia de la Republica de Colombia, 2017: 3), mientras que la identidad de género es "la forma como cada persona se construye, se define, se expresa y vive en relación con su sexo y los elementos de género que adopta" (Consejería de Derechos Humanos de la Presidencia de la Republica de Colombia, 2017: 4). 
Por lo tanto, los aspectos referidos a las orientaciones sexuales y las identidades de género en las personas mayores LGBT generan estigmas sociales, a los cuales se le suman otros factores tales como la edad, la clase social, el sexo (García, 2015). En este sentido, Goffman en su obra Estigma, la identidad deteriorada, sostiene que "no todos los atributos indeseables son temas de discusión, sino únicamente aquellos que son incongruentes con nuestro estereotipo acerca de cómo debe ser determinada especie de individuos" (Goffman, 2006: 13), así, por ejemplo, se esperaría que una persona mayor fuese heterosexual, cisgénero, viviendo en pareja y con nietos, situación que no responde con la diversidad y complejidad social basada en un orden de género binario producto del sistema patriarcal, Butler señala que lo "«masculino» y «femenino» son notoriamente intercambiables; cada término tiene su historia social; sus significados varían de forma radical dependiendo de limites geopolíticos y de restricciones culturales sobre quién imagina a quién, y con qué propósito" (2004: 25).

Por tanto, los estereotipos son una construcción cultural basada en creencias e imaginarios que se desarrollan sobre los grupos sociales en diversos contextos. Su contenido gira entorno a lo característico o diferencial de un grupo (Huici, 1996: 170-176). La idea central para su elaboración está en la diferencia, es decir, sólo lo diferente puede ser objeto de una concepción estereotipada y, por lo tanto, no hay estereotipos sin un grupo social de referencia. Así, los estereotipos son "sociales en su origen, en su referente u objeto (un grupo social) y son compartidos" (Huici, 1996:179).

Por tanto, existen estereotipos de género y de edad, los primeros según la Oficina del Alto Comisionado de las Naciones Unidas para los Derechos Humanos (ACNUDH) se encuentran basados en prejuicios generalizados acerca de los atributos o las características que varones y mujeres poseen o deberían poseer o de las funciones sociales que ambos desempeñan o deberían desempeñar, en consecuencia, los estereotipos de género limitan la capacidad de varones y mujeres para desarrollar sus habilidades y capacidades personales, para tomar decisiones acerca de sus vidas y sus proyectos vitales. En segundo lugar, lo estereotipos de edad se basan en una construcción social que se hace sobre una persona mayor a partir de ideas y prejuicios que recalcan las connotaciones negativas antes que las positivas, fomentado y consolidando una visión deprimente de la vejez.

En el caso de las personas mayores LGBT, se establece una conjunción entre los estereotipos de edad y género que conllevan no solo a invisibilizar sus realidades, sino a aumentar su vulnerabilidad social, generando una estigmatización sobre estas personas, donde "el estigma se convierte en 
un factor fundamental que facilita la discriminación, ya que la estigmatización social puede definirse como una teoría que explica la inferioridad de las personas, en tanto que son diferentes" (Callejas y Piña, 2005: 68).

En este sentido, el termino estigma se concibe como un atributo profundamente descalificador, de manera tal que este atributo que estigmatiza a determinado grupo social puede confirmar la normalidad de otro (Goffman, 2006). Así, a través de la estigmatización se genera una categorización de los grupos sociales y, por ende:

La categorización tiene como fin delimitar y determinar qué es lo que se puede esperar de una persona inscrita en tal o cual categoría, en pocas palabras, es un saber de orden práctico que le permite a los sujetos colegir, a partir de unas pocas señales, qué tipo de relación puede establecer con el otro u otros. Si cercana o distante, agradable o desagradable, o si puede ver al otro como posibilidad o como amenaza (Callejas y Piña, 2005: 134).

Erving Goffman (2006), define tres tipos de estigma, en primer lugar aquellos referidos a las abominaciones del cuerpo, en las cuales se inscriben todas las deformidades y dismorfias del cuerpo; en segundo lugar los estigmas tribales, los cuales se relacionan con la pertenencia del sujeto a cierta raza, nación o credo y que son susceptibles de ser transmitidos a través de la herencia por generaciones; y en tercer lugar, el estigma vinculado a los defectos del carácter, relacionados con deficiencias morales que devalúan a los sujetos como el alcoholismo, la drogadicción, pero también, aquí se pueden considerar los aspectos referidos a la moral de las personas LGBT, pues estas han sido señaladas históricamente como pecaminosas, sujetos de dudosa respetabilidad, incapaces para acompañar la crianza de los hijos o formar una familia, entre otros aspectos.

En el caso de las personas mayores LGBT, también se evidencian los estigmas relacionados con las abominaciones del cuerpo o "estigmas físicos", pues las corporalidades de estos se han venido constituyendo como un importante dispositivo de identidad, por medio del cual se organizan, articulan y construyen las prácticas que les permiten reivindicar sus derechos y visibilizar sus identidades. Así, las diferentes maneras en que se construyen las estéticas de las personas mayores LGBT y en general de todas las personas LGBT pueden ir en contra a los valores y normas corporales hegemónicos, establecidos por un modelo heteronormativo, el cual establece una "matriz binaria según la cual se asignan, clasifican y regulan las identidades de género en las sociedades occidentales" (Gros, 2016: 246), en este sentido, la heteronormatividad o heterosexualidad obligatoria 
de un orden patriarcal define cuáles son las identidades de género inteligibles y correctas, y castiga aquellas que no lo son.

La importancia de la socialización en la construcción de las identidades de género se basa en el hecho que esta es vista como un "constructo multifactorial en tanto obedece a múltiples variables a través de los individuos y las culturas. Implica un proceso de socialización continuo y permanente a través de la vida, en el cual se internalizan los estereotipos y los roles asignados socialmente a hombres y a mujeres, traduciéndose en la ejecución de un comportamiento diferencial y en la posesión de características diferentes" (Rocha, 2009: 256). Por lo tanto, las identidades de género se construyen a lo largo de la vida por las diversas estructuras de socialización que se experimentan en los diversos dominios vitales.

Todo este proceso da cuenta de lo que se ha denominado el paradigma del curso de la vida, según el cual "a lo largo de nuestras vidas estamos expuestos al influjo de fenómenos sociohistóricos que constituyen hitos significativos en nuestra biografía. Estos puntos de inflexión operan como bisagra en el desarrollo de la trayectoria vital, dando como resultado un envejecimiento y una vejez diferencial" (Rada, 2017: 113).

Así, los autores Lalive d'Epinay, Bickel, Cavalli y Spini (2011) sostienen que el "análisis del curso de la vida como institución social requiere poner la atención tanto a nivel estructural —el curso de la vida como modelo o programa institucional - como a nivel de los individuos, de sus experiencias, pensamientos y acciones a través de los cuales construyen sus trayectorias biográficas" (Lalive d'Epinay et al., 2011: 24).

Esta teorización sobre el curso de la vida en el nivel social permite realizar una aproximación a los estigmas y los estereotipos que se tejen alrededor de las personas mayores LGBT, ya que "un modelo de curso de vida no está solo constituido por obligaciones, sino asimismo por oportunidades u opciones; que estructura el desarrollo de la vida humana no solo como un sistema de reglas (normas), sino también como un sistema de asignaciones de recursos (capacidades, competencias)" (Lalive d'Epinay et al., 2011: 24). En este sentido, dichas asignaciones de recursos pueden estar enfocadas en otros grupos sociales dejando de lado a aquellos que se encuentran altamente estigmatizados, por ejemplo, en el caso las mujeres transgénero, quienes estarían entonces limitadas del acceso y permanencia en los ciclos educativos, por tanto, contarían con menores competencias profesionales para hacer frente a sus vidas laborales, en este sentido, "la exclusión de la población trans de las instituciones educativas tiene que ver con comprender la construcción de la identidad de género de las personas 
trans y el sistema binario que rige el sistema educativo y excluye identidades y subjetividades que no caben en este sistema" (Bareiro, 2016: 12).

De otro lado, se encuentra el nivel individual, el cual es el "resultado de una construcción hecha por el sujeto sobre la base de una negociación de los modelos de vida disponibles" (Lalive d'Epinay et al., 2011: 24). Estos mismos autores, afirman que el curso de la vida individual se estructura alrededor de un conjunto de trayectorias más o menos relacionadas entre ellas, en las cuales se desarrolla la existencia individual, incluyendo la trayectoria escolar, familiar, profesional o asociativa.

Los elementos tanto del ámbito individual como social permiten estructurar un análisis sobre los estereotipos y los estigmas que se han creado alrededor de las personas mayores LGBT, y la forma en la cual, estos a través del curso de vida juegan un papel primordial en la construcción de las diferentes formas de envejecimiento y vejez. En consecuencia, la orientación sexual y las identidades de género no son en sí mismas un factor determinante en las formas en las cuales las personas envejecen, sino que por el contrario son las percepciones, imaginarios y prejuicios que sobre dichas características se construyen en un contexto social especifico las que terminarán por influir en los cursos de vida de las personas (Rada, 2017), sin embargo, para el caso de las personas transexuales, adicionalmente a estos factores de tipo social, existen condiciones derivadas de los cambios quirúrgicos y hormonales a los cuales se someten que influyen en su proceso de envejecimiento.

De otro lado, en Colombia la población mayor a 59 años pasó de 2'142,219 en el año 1985, a 5'970,956 en el año 2018. Con un crecimiento anual de 3.5 por ciento, superior a 1.7 por ciento de la población total (Ministerio de Salud y Protección Social, 2019), es decir que en el país 11 por ciento de la población es mayor de 60 años, concentrándose en las ciudades de Bogotá, Medellín, Cali y Barranquilla (Arango y Ruiz, 2015: 1), es decir, las personas adultas mayores en el país residen mayoritariamente en el área urbana.

El aumento de la población adulta mayor ha generado la ampliación de los estudios en envejecimiento en Colombia, entre los cuales se puede mencionar el informe de la Facultad de Medicina de la Universidad de La Sabana y la Asociación Colombiana de Gerontología y Geriatría publicado por la Revista Semana, el cual concluye que para el año 2020 habrá dos personas mayores por cada adolescente, pero sus condiciones de vida serán preocupantes, en aspectos referidos al acceso a las pensiones, los servicios de salud, la vivienda, entre otros, es decir, la pobreza en la población ma- 
yor es multidimensional. Si bien, en Colombia se ha estudiado el tema del adulto mayor son pocas las investigaciones que se enfocan en las personas mayores LGBT, población en la cual la situación de salud mental y el maltrato psicológico podría ser mucho más grave comparada con los adultos mayores heterosexuales (Cardona, et al., 2016) ya que las personas LGBT están expuestas durante sus cursos de vida a situaciones de discriminación o aislamiento social debido a sus orientaciones sexuales o identidades de género, o por lo menos no hayan podido asumirla de manera libre y segura, todos estos aspectos se relacionan con el nivel estructural del curso de vida, referidas a las regulaciones tanto materiales como simbólicos (Lalive d'Epinay et al., 2011: 24).

Este tipo de regulaciones materiales y simbólicas se evidencian en Colombia, ya que en el país no existe una red institucional, familiar ni social consolidada y apropiada que pueda hacer frente a las demandas sociales que esta población requiere. Para el caso de las personas LGBT la situación es más compleja, pues además de estas deficiencias se enfrentan a los prejuicios, estigmas y la discriminación asociados a la diversidad sexual y de género, así como al hecho de que socialmente no se reconocen a las personas mayores LGBT, propiciando su invisibilización, lo que fomenta una mayor vulnerabilidad y riesgo social de exclusión.

En este orden de ideas, Rada (2016), sostiene que "los y las adultas mayores LGBT sufren una triple discriminación: por género, edad y clase social", en este sentido, se hace necesario abordar este tema de manera que se visibilice y se comprenda la realidad de estas personas en el contexto colombiano, logrando su reconocimiento social, además de permitir gestionar los estereotipos, prejuicios y el estigma existente sobre estos adultos. Para tal fin, se debe tener en cuenta lo que Ricardo Iacub manifiesta al respecto al considerar que "el envejecimiento de personas homosexuales y trans es por lo general más complejo debido a la falta de contención familiar, la historia de ocultamiento que la persona atravesó durante su vida y la dificultad de compartir hoy con sus pares su identidad" (2015).

A pesar del creciente interés por el envejecimiento, la realidad que permea a las personas mayores LGBT permanece aún con muchos vacíos, dejando espacio para la discriminación, y el no reconocimiento de sus derechos, como es el derecho a una vida libre de violencia, así se afirma que

La mera existencia de ancianos y ancianas con una orientación sexual o identidad de género diferente a la normativa resulta todavía disonante. Sin embargo, estas personas mayores son víctimas, como mínimo, de una doble discriminación: por razón de su edad (edadismo) y por razón de su orientación o identidad 
sexual (homofobia o transfobia). El maltrato hacia las personas mayores es una forma de violencia presente en nuestra sociedad que muestra una serie de peculiaridades en relación con la población anciana LGBT (Gracia, 2011: 3).

Gracia plantea que la introspección, ligada a una autoimagen como personas LGBT casi nunca se asocia a la palabra vejez, llegar a este estado parece un asunto difícil de asumir a los ojos de la sociedad, en este sentido se niega su existencia y se minimiza su relevancia, así, "estamos ante una población silenciada, invisibilizada $\mathrm{y}$, en buena medida, olvidada por la sociedad, los poderes públicos e incluso la práctica y teoría gerontológica. Una población que, por causa de esa discriminación, ve comprometida la efectiva realización plena de sus derechos humanos" (Gracia, 2011: 3940).

En otro orden de ideas, la autora Inmaculada Mujika (2009) sostiene que la vejez no debe convertirse en una etapa tardía para ser lesbiana, gay o transexual, se debe reconocer lo que se desea, lo que se siente como factor protector e importante para el bienestar, hacerse visible cuando se es mayor debe aportar tranquilidad cuando se afronta la última etapa de la vida.

Entre los estudios que se han realizado en América Latina sobre las personas mayores LGBT destaca el informe sobre "La situación de la población adulta mayor LGBT en Costa Rica, El Salvador y Panamá", el cual fue producido por el Centro de Investigación y Promoción para América Central de Derechos Humanos (CIPAC), este informe muestra las necesidades de atención y cuidado de personas adultas mayores gais, lesbianas, bisexuales, trans e intersex (LGBTI), además de analizar las principales barreras de acceso a los servicios para personas LGBT.

El CIPAC sostiene que

En términos de legislación, se identifica en los tres países la existencia de leyes específicas para la protección de personas adultas mayores. Sin embargo, se trata de leyes que establecen lineamientos generales para la población adulta mayor, mas no contemplan en ningún momento las particularidades de las personas LGBTI adultas mayores. Este vacío, sumado a la ausencia en los tres países de leyes que reconozca las uniones entre personas del mismo sexo, y leyes de identidad de género, colocan a las personas LGBTI adultas mayores en una doble condición de vulnerabilidad y dificultan el respeto igualitario de sus derechos (Suárez, 2015: 2).

Aunque para el caso colombiano existe una normatividad que regula las parejas del mismo sexo y existen algunas normas contra la discriminación de las personas por su sexo, orientación sexual o identidad de género, estas 
dos últimas categorías no se incluyen dentro de la Política Nacional de Envejecimiento y Vejez, por tanto, se desconoce e invisibiliza la orientación sexual en las personas mayores colombianas.

Además, el estudio realizado en Costa Rica, El Salvador y Panamá pone de manifiesto una creciente preocupación e incertidumbre por la percepción del futuro, la idea de residir en un hogar para personas adultas, el no saber qué tipo de trato recibirán, ni como sería manejado su identidad de género u orientación sexual, en este sentido los autores "señalan la necesidad de contar con una respuesta estatal que les permita un mayor acceso a vivienda (a través de créditos y apoyos), mejores pensiones y acceso al trabajo para poder prepararse para su vejez" (CIPAC, 2015: 2).

Los individuos envejecen de múltiples maneras dependiendo de las experiencias, eventos cruciales y transiciones afrontadas durante su curso de vida (Lalive d'Epinay et al., 2011), en este sentido las personas diversas por orientación sexual e identidad de género envejecen de formas diferentes a los heterosexuales, ya que estos debieron afrontar en muchos casos durante su juventud y adultez los prejuicios, el estigma y la discriminación asociada a su diversidad sexual. Estas situaciones condicionaron aspectos tan relevantes en las trayectorias de vida de las personas LGBT como la inserción educativa o laboral, el acceso al sistema de protección social o la conformación de una familia, entre otros aspectos, que vendrían a conformar lo que Lalive d'Epinay et al. (2011) denominan nivel estructural y nivel personal dentro del curso de la vida.

De manera general, la sociedad construida bajo esquemas de género tradicionales espera que una persona adulto mayor (varón o mujer) llegue a la vejez bajo una lógica binaria y heteronormativa, es decir, con una familia nuclear conformada por una pareja del sexo opuesto, con hijos/as y nietos/as, que retorne a su hogar y dependa del cuidado y la atención de su familia, sin embargo, nunca se consideran aspectos relativos a la sexualidad del adulto mayor, y mucho menos en las orientaciones e identidades de género diversas. Por tanto, se desconoce e invisibiliza la diversidad sexual en la vejez lo que genera de entrada una doble discriminación de estas personas, por un lado, la referida a su edad, conocida como edadismo, y de otra parte aquellas situaciones discriminatorias vinculadas a sus identidades sexuales no heteronormativas.

Pero, además, se podría sumar un tercer factor referido a las condiciones socioeconómicas de estas personas que también generan procesos de exclusión y marginación social, que si bien no se consideran en este artículo deben ser señalados por su relevancia en el tema. En este sentido "si 
la persona mayor es invisible para la sociedad, el o la mayor homosexual tiene una invisibilización todavía peor. Se trata de personas que se tuvieron que ocultar toda su vida, ocultar sus parejas, sus deseos, y entonces van quedando en soledad, porque no tienen ese entorno familiar que, mejor o peor, contiene a la persona mayor" (Iacub, 2015: 8).

De manera general, se ha considerado que la vejez de las personas adultas mayores LGBT es diferente a la que puede vivir una persona heterosexual, pero algunos estudios han evidenciado que no existen diferencias significativas, pues ambos se enfrentan a situaciones de discriminación o exclusión respecto a su edad y su nivel socioeconómico, así "la vejez de las personas gais o lesbianas suele ser más común que lo que la gente piensa, tienen los mismos problemas" (Rada, 2016: 1), sin embargo, esta afirmación no se puede generalizar, ya que existen factores específicos que determinan la mayor vulnerabilidad de las lesbianas frente a los gais, $\mathrm{y}$ dicha vulnerabilidad aumenta si se comparan las realidades de estos dos grupos poblaciones con la de las mujeres transgénero (Colombia Diversa, 2020).

\section{Metodología}

Debido a la escasa producción investigativa sobre las condiciones de vida de las personas mayores LGBT en Colombia que permitan el acceso a datos precisos y confiables que den cuenta de las necesidades de atención y cuidado, así como de las redes de apoyo social de esta población, se desarrolló una investigación cualitativa de tipo analítico y descriptivo. El enfoque de la investigación fue hermenéutico-interpretativo ya que buscó aproximarse a los sujetos de estudio para comprenderlos dentro de sus propios marcos de referencia; desde esta perspectiva, se realizó una aproximación a las redes sociales (familia, amigos, vecinos y organización comunitaria) con las cuales cuentan las personas mayores LGBT, además de identificar las necesidades de cuidado y protección que estos tienen.

Sin embargo, este artículo se centrará en realizar una aproximación al estigma y los estereotipos que socialmente se han construido alrededor de la vejez de las personas LGBT, teniendo en cuenta que la diversidad sexual y de género es mucho más amplia, pero para los fines de este estudio solo se consideraron personas mayores gais, lesbianas, bisexuales y transgénero. Se debe considerar que la vejez no es solo una serie de características negativas, entendidas estas como "viejismo", es decir "un conjunto de estereotipos negativos en torno a la vejez que se traduce en actos discriminatorios hacia quienes envejecen, simplemente por la edad que tienen" (Thumala, 2007: 3). En el caso de las personas LGBT el viejismo o 
edadismo se suma a aquellos estigmas y estereotipos existentes frente a las orientaciones sexuales e identidades de género no hegemónicas, de manera tal que estas personas mayores pueden presentar una doble discriminación, en algunos casos y dependiendo las condiciones socioeconómicas de estas personas esta discriminación puede incluir un tercer factor referido a la clase social.

La muestra del presente estudio fue intencionada y no probabilística, a partir de la búsqueda de personas mayores LGBT (Lesbianas, Gay, Bisexuales, Transgénero) que se hallaban residiendo en alguno de los municipios que conforman el Área Metropolitana del Valle de Aburrá, departamento de Antioquia en Colombia. Como estrategia para contactar estos individuos se recurrió a las organizaciones LGBT que trabajan en esta área geográfica, así como a los líderes de estas poblaciones que permitieron referenciar algunas personas mayores.

Los criterios de inclusión establecidos para vincular a los sujetos participantes fueron:

1. Ser personas mayores de 60 años o más, auto identificado como gay, lesbiana, bisexual o de otras orientaciones sexuales.

2. Ser mujer trans adulta mayor (no habla de auto identificación).

3. Contar con estado físico y metal que permita responder a las exigencias del estudio.

4. Aceptar participar de forma voluntaria en la investigación con la firma de un consentimiento informado, mediante el cual se le brindó información certera a los participantes sobre los objetivos, el alcance de la investigación y los posibles beneficios y riesgos de participar en la misma, además se incluyeron apartados referidos a: i) la aceptación de participación libre y gratuita en la investigación, ii) la libre posibilidad de retiro y iii) datos de contacto de los encargados de la investigación en el equipo de la universidad. A través del mismo, se garantizó el consentimiento en la utilización de artefactos como grabadoras o cámaras fotográficas por parte del grupo de investigadores/as. Se hizo un uso adecuado, seguro y confidencial de la información obtenida y se protegieron los nombres de los y las participantes mediante su anonimato.

El instrumento de investigación utilizado en este estudio fue la entrevista semi-estructurada, entendida esta como los "encuentros cara a cara entre el investigador y los informantes, encuentros éstos dirigidos hacia la comprensión de las perspectivas que tienen los informantes respecto de sus vidas, experiencias o situaciones, tal como las expresan con sus propias 
palabras" (Taylor, Bodgan y Devault, 2000). Para el análisis de la información se utilizó el software Atlas.ti versión 7.

La entrevista se estructuró en las siguientes categorías de análisis, en un primer momento se abordaron los temas referidos a i) las características sociodemográficas de los entrevistados, tales como la edad, la orientación sexual y la identidad de género, la ocupación, los ingresos económicos, entre otros; ii) los servicios sociales y específicamente sobre los servicios de salud y su acceso a estos, iii) los actos de violencia y discriminación que hubiesen sufrido; iv) las redes de apoyo y la socialización en esta etapa del ciclo vital, los cuales se vincularon con el tema de la familia; v) la vida en pareja, y para finalizar sobre vi) el conocimiento que tenían los entrevistados sobre sus derechos. El artículo aborda los temas referidos a las características sociodemográficas, a los actos de violencia y discriminación que han sufrido estas personas, así como a las redes de apoyo y a los procesos de socialización de las personas adultas mayores.

Para conocimiento del lector/a es importante señalar que existió gran dificultad en la participación de las mujeres lesbianas y trans. Las primeras por que se negaron a participar y las segundas derivado a su baja esperanza de vida, ya que 80 por ciento de las mujeres transgénero en Latinoamérica mueren a los 35 años o menos según el informe titulado "Violencia contra Personas Lesbianas, Gay, Bisexuales, Trans e Intersex en América", elaborado por la Comisión Interamericana de Derechos Humanos (2015).

En cuanto a las consideraciones éticas, el estudio cumple con las características para ser definido como una investigación sin riesgo, que según la Resolución No 008430 de 1993 del Ministerio de Salud de Colombia, son aquellos "estudios que emplean técnicas y métodos de investigación documental retrospectivos y aquellos en los que no se realiza ninguna intervención o modificación intencionada de las variables biológicas, fisiológicas, sicológicas o sociales de los individuos que participan en el estudio" (Ministerio de Salud de Colombia, 1993: 3).

\section{RESULTADOS Y DISCUSIÓN}

La muestra se conformó a través de individuos que aceptaron participar voluntariamente en la investigación, los cuales fueron referenciados por líderes de la población LGBT y de algunas de sus organizaciones, siendo una muestra por conveniencia. 


\section{Características sociodemográficas del adulto mayor LGBT}

La mayor parte de los participantes en el estudio eran gais, con estudios universitarios, los cuales tenían acceso a una pensión, mientras que otros aún continuaban trabajando, en el caso de las mujeres lesbianas y transgénero, estas tenían estudios medios y en el momento de la entrevista desarrollaban actividades laborales por cuenta propia.

Tabla 1: Características sociodemográficas de los sujetos participantes

\begin{tabular}{lllll}
\hline Nombre & Edad & Identidad sexual & Nivel educativo & Actividad habitual \\
\hline Elías & 68 & Gay & Posgrado & Pensionado $^{*}$ \\
Fermín & 61 & Gay & Posgrado & Independiente $^{*}$ \\
Guido & 62 & Gay & Universitario & Pensionado \\
Honorio & 61 & Gay & Posgrado & Pensionado \\
Joel & 62 & Gay & Técnico & Rentista \\
Lucas & 60 & Gay & Posgrado & Empleado \\
Dara & 60 & Lesbiana & Bachillerato & Independiente \\
Sara & 60 & Mujer transgénero & Bachillerato & Independiente \\
Jana & 60 & Lesbiana & Secundaria & Pensionada \\
Primo & 60 & Gay & Posgrado & Independiente \\
\hline
\end{tabular}

* De acuerdo con el Ministerio del Trabajo de Colombia, independiente "es aquella persona que no está vinculada a una empresa mediante un contrato de trabajo, sino mediante un contrato por prestación de servicios, y son remunerados bajo la figura de honorarios o comisiones, o los que trabajan por cuenta propia"

Fuente: elaboración propia, 2018.

\section{El curso de vida del adulto mayor LGBT}

Los cursos de vida cobran significado en los resultados de la investigación ya que posibilitan una comprensión de las situaciones personales que cada uno de los entrevistados debió enfrentar a lo largo de su vida, las cuales han estado influenciadas por sus orientaciones sexuales o sus identidades de género. Sin embargo, como lo sostiene Rada (2017), los procesos de envejecimiento no se ven afectados directamente por la diversidad sexual, sino por los prejuicios, los estereotipos y el estigma que se ha generado socialmente sobre esta, lo cual influye en los cursos de vida de las personas LGBT.

El artículo realizará una aproximación a los cursos de vida de los entrevistados, los cuales según Lalive d'Epinay et al. (2011), se estructuran en forma de trayectorias más o menos relacionadas entre sí, que incluyen los 
aspectos educativos, familiares, profesionales y sociales, de esta manera se pueden observar de forma general las trayectorias de las personas participantes en el estudio, las cuales se describen a continuación.

Para el caso de Sara, una mujer transgénero de 60 años de edad, su adolescencia se vio marcada por su identidad de género, ya que ésta no se ajustaba a lo que socialmente se esperaba de su sexo. Esta situación le implicó múltiples casos de discriminación en el ámbito laboral y un distanciamiento con su familia, situación que acarreó el debilitamiento de las redes de apoyo familiar, y problemas para el acceso al mercado laboral, siendo una de sus alternativas de subsistencia el trabajo sexual, mediante el cual logra atender sus necesidades básicas. Además, esta mujer manifiesta que la discriminación también ha provenido desde la propia población LGBT, donde se hace evidente la endodiscriminación, en sus palabras:

La mujer trans es discriminada hasta en el colectivo LGBT por el hombre gay, ya que traté de entrar a una peluquería donde trabajan muchachos gais y por medio de ellos fui rechazada, [...], incluso por parte de la comunidad LGBT que no nos dejan entrar a discotecas, en restaurantes, en peluquerías donde trabajan muchachos gais y todo eso, he sido discriminada toda mi vida" (Sara, 60 años, mujer transgénero).

Algunos estudios sostienen que la esperanza de vida de las personas trans es de un "mínimo de 35.5 y un máximo de 41.25 años, mientras que la esperanza de vida en Latinoamérica ronda los 75 años" (Ulises, 2013: 54). En este sentido, Sara ha superado la esperanza de vida promedio para las mujeres transgénero, teniendo en cuenta que es una mujer que vive con VIH/Sida y que, además a lo largo de su vida ha sufrido de diferentes formas de violencia y discriminación.

De otro lado, encontramos a Jana, una mujer lesbiana de 60 años de edad, cuyo curso de vida se vio condicionado por una serie de controles sociales sobre su sexualidad, como lo manifiesta Guasch "la actividad sexual no es prohibida: se recomienda. Pero dentro de un orden. Con pautas, reglas, directrices" (1993: 11), y en este sentido, Jana proveniente de una familia conservadora, debió contraer matrimonio a los 20 años de edad, posteriormente procrear a sus dos hijos. El control social sobre su sexualidad se evidencia en el siguiente testimonio:

Pues, fue normal (la relación con el esposo), porque lo único extraordinario que hubo fueron mis dos hijas, sí me case enamorada, pero ya luego, ya recordando, como que hubiera estado muy enamorada de él o que él fuera el amor de mi vida, no. Si yo me hubiera quedado aquí (refiriéndose a su pueblo natal), 
no me hubieran gustado las mujeres, porque yo después de quedar viuda tuve muchos hombres (Jana, 60 años, lesbiana).

El proceso de autoaceptación de Jana fue muy complejo, manifestando que en algún momento de su vida llegó a sentirse homofóbica, sin embargo, después de asumir su orientación sexual la vive plenamente, para lo cual buscó apoyo tanto psicológico como espiritual, en sus palabras:

Fui a una psicóloga, por el Parque Bolívar, particular porque yo no me aceptaba, fui hace un año y no volví, porque yo iba porque no me aceptaba y ya ella se fue. Pero también fui donde un cura amigo mío, que me ha ayudado mucho al respecto y yo hablo mucho con él. Me ha ayudado en la aceptación (Jana, 60 años, lesbiana).

Elías, por su parte, es un hombre gay de 68 años que ejerció el sacerdocio hasta sus 35 años, situación que marcaría su vida personal, ya que, aunque tenía asumida su orientación sexual, el hacer parte de la iglesia católica lo obligaba a reprimir todos sus deseos, en sus palabras:

En el tiempo de la iglesia sencillamente tenemos que actuar todos los sujetos de la iglesia romana como si fuéramos asexuados, casi que incorpóreos y no se habla de sexualidad, no se deja ver. Quienes viven una relación homo-erótica o hetero-erótica la viven clandestinamente, mandato de la iglesia y de sus propias costumbres, no tuve problema porque yo me monté en un idealismo en esos años en que era posible vivir sin vivir la sexualidad, ni el afecto particular, y resulta que la naturaleza se impone, eso me duró a mi hasta los 35 años (Elías, 68 años, gay).

En el año de 1994, Elías se retiró de la iglesia y desde entonces presta sus servicios en el ámbito espiritual a las personas que lo necesitan, así, su experiencia personal y profesional le ha permitido empoderarse como líder dentro de la población LGBT, gestionando una organización de base comunitaria que propende por el bienestar de esta población.

Por su parte, Primo es un hombre gay de 60 años de edad, quien manifiesta que su familia asumió de manera adecuada su orientación sexual, en sus palabras: "Digamos en mi casa se me permitió ser libremente homosexual" (Primo, 60 años, gay).

Este testimonio hace evidente la función de control social que ejercía su familia, pues sin la aprobación que obtuvo por parte de sus miembros no hubiera podido asumir su orientación sexual, situación que además vino a determinar su posicionamiento social frente al tema de las sexualidades no hegemónicas, así: "Cuando yo salí del closet, salí con toda, y de una vez 
me puse en el plan del activismo... yo me hago valer como una persona que defiende unos procesos que estaban arrancando... a las malas o las buenas tuve que decir" (Primo, 60 años, gay).

En consecuencia, después de revelar su orientación sexual frente a su familia el entrevistado asume una postura de empoderamiento y activismo por la lucha de los derechos de la comunidad LGBT, la cual mantiene hasta la actualidad.

En los casos de Jana, Primo y Elías se hacen evidentes los controles sociales provenientes de la familia y la religión, los cuales tiene como finalidad preservar el orden social establecido, a través de la vigilancia que se establece sobre las denominadas conductas desviadas, que son las que afectan con mayor o menor intensidad el orden social, coincidiendo con lo que Erving Goffman (2006) define como los estigmas por defectos de carácter.

De otra parte, encontramos a Honorio, un varón homosexual de 61 años de edad, el cual tuvo una infancia marcada por parámetros heteronormativos que provenían desde diferentes ámbitos sociales, tales como la iglesia, la familia y la escuela, el entrevistado manifiesta que: "Los principios que me infundió la familia, la escuela, la iglesia y la sociedad tienen mucha fuerza y uno los seguí sin cuestionarlos" (Honorio, 61 años, gay).

Estos ámbitos ejercían una función como controles sociales sobre la sexualidad que llevaron a Honorio a cohibir y ocultar su orientación sexual durante su juventud: "Durante mi adolescencia mi sexualidad fue muy secreta, no me manifesté como era, vivía en mi mundo" (Honorio, 61 años, gay).

Sin embargo, al ingresar a la formación universitaria Honorio pudo redescubrir su orientación sexual, y vivirla de manera libre, en sus palabras:

En la universidad realice estudios de filosofía, la filosofía me ayudo cantidades, los filósofos que leí me ayudaron muchísimo, me di cuenta que, lo más importante es la felicidad personal, más que lo que desea la familia, la sociedad o la iglesia, lo más importante es mi deseo personal y ese deseo se debe vivir y manifestarlo con lógica y cuidado" (Honorio, 61 años, gay).

Durante ese proceso, Honorio manifiesta haber encontrado en el conocimiento la oportunidad de emanciparse de un orden heteronormativo, él sostiene que: "La heterosexualidad es más una norma que dicta la sociedad" (Honorio, 61 años, gay).

El curso de la vida de Honorio pone en evidencia el papel que ejerce la heteronormatividad sobre las personas LGBT, y cómo influye esta en las 
decisiones que deben tomar a lo largo de sus trayectorias de la vida en los diferentes ámbitos, ya sean familiares, laborales o sociales, ya que "aquellos que no cumplen con el papel que les ha sido asignado por la heteronormatividad sufren una sanción social que puede ir desde el desprecio y el ostracismo hasta la abierta violencia física" (Gros, 2016: 254).

Para el caso de Joel, un varón gay de 62 años de edad, su juventud se desarrolló en un contexto rural, donde el hecho de aceptar su orientación sexual estaba condicionado por una serie de prejuicios, estereotipos e imaginarios que se tenía frente a las orientaciones sexuales no heterosexuales, en sus palabras:

En mis tiempos de niñez fue muy complicado, siendo un campesino en un pueblo de no más de 500 habitantes, en ese entonces, hace 55 años, el ser gay era una enfermedad, entonces era algo que se tenía que tener oculto (Joel, 62 años, gay).

Este contexto más conservador y donde se patologizaba la homosexualidad, vendría a determinar la manera en la que el entrevistado asumiría su orientación sexual a lo largo de su niñez y juventud, así: "En la primaria y secundaria cuando se hablada de sexo, uno se sonrojaba y sabía que uno era diferente" (Joel, 62 años, gay).

Esta situación traería como consecuencia que Joel, al no poder manifestar su orientación sexual de manera libre y segura terminara por distanciarse de su familia y su círculo social más próximo, Joel expresa que: "Con mi familia fui yo el que me alejé...me sentía diferente, me aislé siendo una persona muy joven a los 18 o 19 años" (Joel, 62 años, gay).

El caso de Joel entra en contraposición con el caso de Primo, poniendo en evidencia la importancia de la aceptación familiar y la necesidad de vincularla en los procesos para asumir la orientación sexual en la etapa de la juventud.

Lucas, por su parte, es un varón homosexual de 60 años, quien desde muy joven pudo experimentar y reconocer su orientación sexual, pero evidenció diversos tipos de controles sociales que provenían de diversos ámbitos, en sus palabras:

Por crecer en una familia tradicional hubo cierto ocultamiento, en el colegio hubo algún contacto sexual, pero se quedó en letargo, a medida que fui creciendo tuve algunas novias, hasta que después de graduado tuve relaciones con una persona gay y ese fue la revelación, que ese era mi camino, lo que me gustaba, desde allí empecé a vivir mi sexualidad plenamente (Lucas, 60 años, gay). 
Dara es una mujer lesbiana de 60 años de edad, la cual desarrollo su vida en un contexto familiar patriarcal, donde se le inculcó que siendo la mayor de las hijas debía conservar un sistema heteronormativo basado en el matrimonio y la reproducción, en sus palabras:

En mi juventud fui muy cómoda en el hogar, no me interesaba ahorrar, estudiar, no me interesaba una pensión, yo era de las personas que pensaba si me trajeron al mundo es porque me tiene que mantener, fui muy inestable, por miedos, temores, como la forma de ese papá incluirle a uno el miedo a los hombres, el machismo, muchas cosas (Dara, 60 años, lesbiana).

El contexto familiar influyó en la manera en la cual Dara asumiría tanto su orientación sexual como su proyecto de vida, así por más de 15 años no adquirió responsabilidad alguna de tipo académico o laboral: "Nunca ahorre, nunca me proyecte una forma de vida diferente, lo que trabajaba me lo gastaba en las parrandas, trabaje en empresas, pero nunca lo suficiente como para decir me van a devolver una pensión" (Dara, 60 años, lesbiana).

Por otra parte, el padre de Dara siempre ejerció un control sobre su orientación sexual, o por lo menos influyó en que esta mujer no la asumiera, ella manifiesta: "Yo tuve tapada mi vida por más de 15 años, yo no salía del closet.... por ese miedo a mi papá" (Dara, 60 años, lesbiana).

El proceso de auto-identificación de Dara fue complejo, debido a los controles que ejercía tanto su padre como aquellos que provenían de su contexto social y familiar, lo cual la llevó a asumir una doble vida. Al fallecer el padre de Dara y sin contar con una red de apoyo familiar y ocultando su orientación sexual, esta mujer entró en un proceso depresión que la conduciría a abusar del alcohol como una medida para aliviar sus penas, en la actualidad Dara hace parte de un grupo de alcohólicos anónimos y aunque su familia conoce su orientación sexual se niegan a reconocerla plenamente.

Fermín, es un hombre gay, de 61 años de edad con estudios de posgrado, quien manifiesta que a lo largo de su vida no ha tenido problemas vinculados con su orientación sexual, además, ha contado con el apoyo de su familia, quienes nunca han cuestionado su homosexualidad. En los relatos de Fermín, se evidencia que considera fundamental para ser respetado y no discriminado, tanto por su familia como por la sociedad en general, mantener un comportamiento que no se aleje de la masculinidad hegemónica, en sus palabras: "Porque yo soy directo y al grano con lo mío, pongo primero mi profesión y mi comportamiento que mi inclinación sexual" (Fermín, 61 años, gay). 
De otro lado, está Guido, un varón homosexual de 62 años de edad, que a través de su trayectoria de vida se debió enfrentar a una serie de actos de discriminación originados en su orientación sexual. Estas situaciones no permitieron que durante su juventud pudiera asumir abiertamente y de manera segura su identidad sexual, ya que consideraba que esta iba en contra de los parámetros establecidos socialmente, Guido manifiesta que: "No poderlo decir [Su orientación sexual], porque si lo decía, yo estaba irrespetando a la gente, y la gente tenía el derecho a reclamar, insultar, porque se lo hacían ver a uno como algo normal" (Guido, 62 años, gay).

El testimonio de Guido, corresponde con los estigmas vinculados a los defectos de carácter definidos por Goffman (2006), los que finalmente, conducen a actos de discriminación que restringen los derechos y las oportunidades, al funcionar como barreras en el acceso a la vida social plena y a los servicios que necesitan las personas LGBT.

En la mayor parte de los testimonios sobre el curso de vida de los entrevistados aparecen los controles sociales representados por la familia, las instituciones educativas, la religión y los pares como elementos primordiales que condicionan y controlan la sexualidad de los entrevistados, los cuales los llevaron a invisibilizar y a mantener sus vidas sociales y sexuales en el anonimato, así que "producto de estas trayectorias signadas por la invisibilidad, gran parte de las personas comenzaron a quedar solas, aisladas y vulnerables en su adultez mayor" (Rada, 2017: 119).

\section{El aislamiento y la soledad del adulto mayor LGBT}

Existe una idea generalizada de que el destino del adulto mayor LGBT es el aislamiento y la soledad (García, 2015), constituyéndose dicha situación en un estereotipo respecto a esta población, lo cual no responde necesariamente a la realidad. En algunos de los casos estudiados se observa que la soledad es asumida como una decisión personal que le permite al individuo su independencia y libertad, situación que estaría determinada por sus cursos de vida, ya que en la juventud o adultez estas personas no habrían podido asumir libremente su orientación sexual debido a diversos controles sociales, entre ellos sus propias familias.

De otro lado, existen aquellas personas mayores LGBT que se han visto abocados a la soledad y al asilamiento debido a las condiciones de pobreza en las cuales viven, situación que tiene una fuerte relación con el debilitamiento de las redes de apoyo social y familiar, y la exclusión y discriminación a la cual se han visto sometidos especialmente por cuestiones de identidad de género (Rada, 2017). 


\section{Elección de la soledad como un estilo de vida}

En algunos casos los entrevistados han optado por una vida en soledad como decisión propia, pero también asentada en el estereotipo del "gay adulto mayor solitario", pues desde jóvenes se han preocupado por mejorar su nivel socioeconómico, de manera que al llegar a la vejez puedan hacer frente a todas sus necesidades evitando la dependencia, es decir, "habrían aprendido la importancia de la independencia personal a la hora de planificar su envejecimiento" (Morrow, 2001: 163 citado en Gracia, 2011: 21), en palabras de uno de los entrevistados: "Confío en Dios, me he preparado económicamente, porque si le tengo que pagar a una enfermera le pago, o si tengo que ir a algún lugar lo pago, tengo mi medicina prepagada y el apoyo de mi familia" (Honorio, 61 años, gay).

Esta situación también ha sido evidenciada en otros países, tal como lo reconoce Acuña, quien manifiesta que en sociedades como la canadiense "predomina la soledad como un estilo de vida" 2014: 12) dentro de la población adulto mayor LGBT.

Otro de los aspectos que favorece esta elección, es el hecho que las personas mayores LGBT tienen un mayor grado de resiliencia e independencia (Gracia, 2011), la cual se ha forjado debido al estigma y la discriminación que a lo largo de sus vidas han debido afrontar para asumir sus identidades sexuales, de tal manera que, algunas de las personas mayores entrevistadas elijan estar en su vejez solos, ya que a lo largo del curso de vida han hecho frente a gran número de situaciones de discriminación y desprecio que les han permitido generar estrategias de resiliencia.

Yo crecí una generación donde la homosexualidad era prohibida, donde no me lo decían, pero en el ambiente decían los maricas, los cacorros ${ }^{1}$, los perezosos, ${ }^{2}$ nos hacían a un lado, nos molestaban, nunca lo manifesté a nadie y crecí así con ese imaginario de no poderlo decir porque si lo decía yo estaba irrespetando a la gente, y la gente tenía el derecho a reclamar, insultar porque se lo hacían ver a uno como algo normal (Guido, 62 años, gay).

Además, desde sus perspectivas de vida se han valido por sí mismos, alejados de sus familias, y con una red de amigos y pares que les han permitido la independencia, en la cual están acostumbrados a vivir, sin que esto signifique que no posean redes sociales e institucionales de apoyo, incluidas las denominadas familias de elección confirmadas por sus amigos.

\footnotetext{
${ }^{1}$ La palabra cacorro hace referencia a aquellos varones que penetran analmente a otro como parte de sus prácticas sexuales, no necesariamente se autoidentifican como homosexuales.

Sinónimo de flojo o vago.
} 


\section{Pobreza y la soledad del adulto mayor LGBT}

Autores como Acuña (2014) hacen referencia a que la soledad en el contexto de la vejez está relacionada con las condiciones de aislamiento y carencia de apoyo afectivo, social y económico, situación que no es evidente en los sujetos entrevistados en este estudio, especialmente en el caso de los varones homosexuales, caso contrario sucede con la mujer transgénero, donde las carencias de apoyo de diversa índole están presentes en sus respuestas:

Mi familia sabe de mi identidad de género y reaccionaron de manera deportiva e indiferente, porque en mi familia nunca he tenido privilegios. En la parte económica ellos no estaban dispuestos a compartirla conmigo por motivos de discriminación familiar, entonces no cuento con apoyo familiar (Sara, 60 años, Mujer transgénero).

En este mismo sentido, algunos de los varones homosexuales entrevistados manifiestan que la estabilidad económica asegura su bienestar en la vejez, sosteniendo la importancia de una pensión o el acceso a recursos económicos para mantener la salud física, mental y los vínculos familiares, situación que corrobora que "la variable ingresos es muy importante: a mayores ingresos menos soledad" (García, 2015: 3). En palabras de un entrevistado:

No van a reuniones familiares porque su familia lo evita, como estamos en una sociedad capitalista cuando la gente tiene los recursos, entonces tenemos una estabilidad psíquica y económica. Pero una persona de edad que no tenga una jubilación o un trabajo, sí sufre mucho de maltrato en especial por su homosexualidad (Honorio, 61 años, gay).

Además, este testimonio pone en evidencia la discriminación acumulativa, es decir, en la que se adicionan los efectos de la discriminación repetitiva, o en un número de ocasiones únicas pero basadas en características diferentes (HelpAge, 2017), es decir, discriminación por razones de edad, orientación sexual, identidad de género o estatus socioeconómico que se presentan de manera simultánea, en el caso, de las mujeres transgénero esta discriminación es más evidente.

La situación a la que se enfrentan las mujeres transgénero en la vejez es mucho más complicada que la de lesbianas, gais y bisexuales, especialmente porque su identidad de género las hace más visibles y proclives a la discriminación de todo tipo. Además, esta discriminación debilita tanto sus relaciones familiares como sus redes de apoyo afectivo, material o social, 
por ende, el "vivir solo en la vejez es un factor que puede contribuir en gran medida a la pobreza" (Gimeno, 2014: 61).

De otro lado, la vejez también afecta de manera directa los ingresos de las mujeres transgénero que se dedican al trabajo sexual, lo que influye en sus condiciones de vida, Sara manifiesta que:

La parte moral y psicológica me afecta, el hecho de que alguien me saque el cuerpo me da tristeza, es cuando alguien me saca el cuerpo por la edad, es la utilidad que esa persona me deja de brindar la parte monetaria, porque lo necesito para subsistir, lo que me dejo de ganar porque otra persona que está más joven lo puede hacer (Sara, 60 años, Mujer transgénero).

Así, para el caso de las mujeres transgénero "la soledad en la que se encontraron en la juventud, la falta de educación y la discriminación sexual, les ofrecían la prostitución como única alternativa de supervivencia ante una situación de pobreza y de marginalidad que las acompañaría durante toda su vida" (Rada, 2017:130). En este sentido, es necesario considerar en el diseño de las políticas públicas los contextos de exclusión y marginación a los cuales se ven sometidas las mujeres transgénero, de manera que se pueda asegurar, entre otras acciones, su permanencia en la educación, eliminar la discriminación en los ámbitos educativos y laborales, y disminuir la incidencia de la violencia en su contra.

Vale la pena decir que son las mujeres, ya sean estas lesbianas o transgénero, las más afectadas por la pobreza y la marginalidad, pues si se compara la situación económica de los varones homosexuales con ellas, se observa que los primeros han accedido mayoritariamente a pensiones contributivas o cuentan con ingresos estables, mientras que las mujeres continúan trabajando en empleos precarios o aquella que accedió a una pensión lo hizo por sustitución. Esto se debe a la desigualad de género, donde las construcciones socioculturales sobre el género permean todas las esferas de la vida humana generando diversas inequidades en las condiciones económicas, educativas, sociales, políticas, entre otras, de las cuales no escapan las lesbianas y las mujeres transgénero.

\section{La salida del armario del adulto mayor LGBT}

El segundo estereotipo hace referencia al hecho de pensar que las personas mayores están más "armarizadas" que las personas jóvenes (Apoyo Positivo, 2019) debido a las situaciones de discriminación a las cuales se han visto sometidas en el curso de sus vidas. lo que dificultaría que asuman abiertamente su identidad sexual, sin embargo, algunos de los testimonios 
de los entrevistados refutan esta idea, ya que en ellos se observa su recorrido como activistas, tal es el caso de Primo:

A partir del año 1998 empecé a trabajar y abrir puertas con el tema LGBT, desde ese año centré mí quehacer y ejercicio profesional en trabajar con población LGBT [...] fui de los que abrimos puertas [...] en la ciudad de Medellín con el tema de las diversidades sexuales (Primo, 60 años, gay).

En este y otros casos las actividades en defensa de los derechos de la población LGBT datan de procesos emprendidos desde la juventud por parte de los entrevistados que les permitieron empoderarse $\mathrm{y}$, por tanto, mantenerse en el activismo en la actualidad, así aquellas personas mayores LGBT que pudieron 'salir del closet', construir redes de apoyo familiares y sociales, y asumir en libertad sus identidades sexuales tienen envejecimientos exitosos (SentidoG, 2015; Iacub, 2015).

Los varones homosexuales entrevistados participan de manera activa en la vida gay de sus ciudades, asisten a lugares de homosocialización y en algunos casos hacen parte de organizaciones sociales, esto

demuestra que hay personas que se muestran dispuestas al activismo precisamente cuando se jubilan y dejan de sentir la presión del trabajo y de los compañeros; cuando una persona se jubila es cuando dispone de más tiempo libre, cuando desea sentirse útil, cuando tiene ya poco que perder (Gimeno, 2014: 68).

En este mismo sentido, algunos de los entrevistados manifiestan que en esta etapa de sus vidas no tienen miedo ni les importa lo que piensen sus familiares y amigos respecto a su orientación sexual, y, por ende, es más fácil para ellos asumir su orientación sexual de manera libre, en palabras de un entrevistado:

Sí, todas las personas de la época mía tuvimos que padecer eso [discriminación], tuvimos que evitar hablar, evitar de ser muy obvios para evitar discriminación, entonces mi generación creció así y salimos adelante gracias a que fuimos capaces de guardar eso, pero también de salir adelante ante los demás. Y en esta etapa de mi vida no me interesa el qué dirán, pero no me gusta conversar de eso ni darle explicación a nadie (Guido, 62 años, gay).

Sin embargo, la salida del closet para las personas mayores está determinada por factores de tipo social y económico, al igual que sucede con la soledad, así la pobreza condiciona ambos aspectos, pues el hecho de carecer de autonomía económica y redes de apoyo limitará en buena 
medida que el adulto mayor asuma su orientación sexual, o en otros casos empujará a estas personas a volver al "closet", en este sentido se ponen el juego tanto el nivel estructural que condiciona el individual que constituyen el curso de vida (Lalive d'Epinay et al., 2011). Un testimonio muestra esta situación:

El adulto mayor diverso tiene una problemática supremamente delicada, el adulto mayor diverso está obligado a vivir en el closet, si no tiene una pensión, si no ha cotizado, tiene en la mayoría necesidades insatisfechas. Yo conozco a muchos viviendo en una pieza, con 300 mil pesos $^{3}$ mensuales y totalmente arrinconados, totalmente excluidos de su ambiente familiar y sentados en una banca, impacta y el estado no tiene conciencia de esta realidad (Primo, 60 años, gay).

Algunos de los entrevistados sostienen que resulta necesario ocultar la orientación sexual en el área laboral, pues la prioridad es el ejercicio profesional y la estabilidad económica, pero señalan que existe una mayor discriminación por orientación sexual en el caso de las mujeres, así:

Por la condición sexual en cuestión de trabajo o en busca de empleos automáticamente lo señalan y lo juzgan, desafortunadamente dan con gente más joven que no está preparada para manejar este tipo de situaciones, se siente rechazo en esa parte, yo no lo he experimentado, pero si me he dado cuenta de amigos que por su condición sexual en entrevistas y más en el caso de una mujer en una entrevista enfrentan más el rechazo (Fermín, 61 años, gay).

De tal modo que, asumir la orientación sexual resulta un asunto que involucra no solo los aspectos emocionales personales, es decir el nivel individual, sino que se vincula con su estabilidad y bienestar económico, relacionado con el nivel estructural, generando una tensión entre ambos aspectos, tensión que cada individuo afronta de manera diferente, pero que en el caso de las personas mayores LGBT implicaría un regreso a la invisibilización de su orientación sexual debido a su dificultad para acceder al mercado laboral en esta etapa de sus vidas.

\section{La sexualidad del adulto mayor LGBT}

Un tercer estereotipo está referido a la sexualidad, donde se suele considerar a las personas mayores LGBT como seres asexuados, originando que la sexualidad en estos sea vista como un asunto inconcebible para esta etapa de la vida, tal como se evidencia en este testimonio:

3300 mil pesos colombianos corresponden aproximadamente a 94 dólares americanos. 
Yo creo que es parte de la discriminación del miedo de nombrar ciertas realidades humanas y que cuando esas realidades están presentes en la vejez son vistas como indecentes, impúdicas, feas, antiestéticas, en nuestra cultura se habla con desdén de los viejos maricones (Elías, 68 años, gay).

Por tanto, la sexualidad en las personas mayores se considera que no existe o que no es necesaria y si sucede, es vista como anormal, especialmente en las personas mayores LGBT, precisamente porque su sexualidad es el factor diferenciador, esto

parece lógico, puesto que es lo que les singulariza ya que, como recuerda Bourdieu (2003:144), la particularidad de la relación de dominación simbólica que se ejerce sobre los homosexuales reside en que no va unida a los signos sexuales visibles sino a la práctica sexual (Gracia, 2011: 3).

Esta situación origina sobre la sexualidad del adulto mayor LGBT dos estigmas, uno referido a la edad, al concebirlos como personas carentes de sexo o asexuados, y de otro lado debido a su orientación sexual o identidad de género al catalogarlos como consumidores excesivos de sexo, en este sentido, Gimeno (2014) sostiene que las personas mayores LGBT son visto como

seres sin sexo o voraces sexualmente cualquier indicación de que son sexualmente activos resultará especialmente castigada socialmente, especialmente porque esa voracidad sexual, según el imaginario colectivo al uso, se ceba en niños y adolescentes (Gimeno, 2014: 47).

Por tanto, "valiéndonos de este supuesto practicamos diversos tipos de discriminación, mediante la cual reducimos en la práctica, aunque a menudo sin pensarlo, sus posibilidades de vida" (Goffman, 2006: 15). En relación a esto, Elías manifiesta que: "Se les considera [a las personas mayores LGBT] enfermos, morbosos, etc... una palabra bonita que un hombre adulto mayor le diga a un hombre joven es mal recibida" (Elías, 68 años, gay).

Así, la sexualidad en el adulto mayor, pero especialmente en el adulto mayor LGBT, debe enfrentar fuertes prejuicios, ya que socialmente suelen ser descalificados, catalogándose como enfermos, morbosos o "viejos verdes", generando sobre ellos un estigma social, y por ende se les niega la oportunidad de disfrutar una vida sexual plena en esta etapa de sus vidas. Así, el no reconocimiento de la sexualidad en el adulto mayor LGBT los termina invisibilizando, por tanto 
la idea extendida de que los ancianos son seres asexuados tampoco ayuda a visibilizar socialmente a este colectivo: parece más bien sugerir que, a medida que se van haciendo mayores, dejan de ser lesbianas, gais o transexuales para convertirse en alguien sin sexo (Mujika, 2009: 6).

Algunos de los entrevistados manifiestan que tienen una vida sexual activa, y la realidad es que la mayoría de los gais mayores de 65 años tienen vida sexual activa (Kelly, 1977; CEPAL, 2019),

Yo soy muy inquieto, segundo yo no me considero adulto, yo me considero un hombre demasiado vital, mis años no los tengo tan marcados, por ejemplo, mi papá, se pensionó y se anuló, tengo una vida sexual sana, placentera (Primo, 60 años, gay).

Sin embargo, como ya se mencionó la sexualidad en esta etapa de la vida es ignorada, pues se considera que en la vejez se pierden capacidades para el disfrute pleno de la sexualidad, ya que las transformaciones que sufre el cuerpo en el proceso de envejecimiento se asocian de manera directa con los aspectos sexuales y esta asociación se realiza a través de "ciertos prejuicios respecto al placer y el erotismo de las personas adultas mayores" (Acuña, 2014: 21).

Todos los aspectos relacionados con los estigmas vinculados con la vejez y las orientaciones sexuales no hegemónicas y otras identidades de género crean una situación de vulnerabilidad para las personas mayores LGBT, ya que al desconocerse su sexualidad también se desconocen las necesidades de promoción y prevención en materia de salud sexual, así el acceso a información al respecto que tienen las personas mayores es muy limitado.

No he recibido información de sexualidad en citas médicas. En espacios de amigos si he hablado del tema. Con organizaciones, con activistas dediqué algún tiempo a repartir preservativos. Todo el mundo debe cuidarse, porque todos vivimos la sexualidad. He recibido información del VIH con amigos, conferencias, no hay algo claro con el tema (Honorio, 61 años, gay).

Además, los avances en farmacología han contribuido a que la actividad sexual de los varones mayores gais o bisexuales sea más permanente y activa, un entrevistado manifiesta que:

Hay un problema muy grave, de salud pública, existe mucho adulto mayor viviendo con VIH, y hay una razón lógica, el viagra como medicamento se convirtió en el segundo momento de placer [...] a raíz de esta situación hay 
muchas personas mayores viviendo con VIH, esa es una realidad (Primo, 60 años, gay).

Por tanto, es evidente que las personas mayores son sexualmente activos, pero socialmente su sexualidad es invisibilizada y, por ende, no existen campañas de promoción y prevención en salud sexual que tengan como población objetivo a este colectivo social, puesto que estas generalmente están destinadas a varones jóvenes. Esta situación trae importantes consecuencias para las personas mayores como un aumento en la vulnerabilidad frente a las infecciones de transmisión sexual, incluyendo el VIH, además de sentimientos de frustración al no brindarse información para su edad que garantice el ejercicio pleno de sus derechos sexuales.

Así, los estigmas sociales que existen sobre la sexualidad en las personas mayores sumados a los prejuicios referidos a las diversas orientaciones sexuales no normativas y otras identidades de género, generan un tipo de discriminación acumulativa que afecta de manera directa el disfrute pleno y responsable de la sexualidad por parte de las personas mayores LGBT. En un primer momento estos adultos se niegan el propio disfrute de su sexualidad al considerar que es una situación normal del envejecimiento, un entrevistado manifiesta que: "En la edad en la que ya estoy, hay algo muy importante, es que ya no prima la pasión, sino la razón, es ese paso que se da de ser joven al llegar a esta edad" (Honorio, 61 años, gay).

Por otra parte, una vida sexual no placentera puede ocasionar otro tipo de problemas para la persona, por ejemplo, aquellos relacionados a la salud mental, como depresión, angustia, inseguridad, entre otras.

"Digamos que, en el adulto mayor diverso, por eso que una gran mayoría están en el closet, no tiene sus necesidades sexuales satisfechas y sufren mucho, y son fáciles de manipular" (Primo, 60 años, gay).

De manera general, los testimonios de los entrevistados evidencian un estigma sexual, el cual

puede manifestarse de tres formas: una, de forma estructural al incrustarse en las instituciones sociales e imponer un desequilibrio de poder que pone en desventaja a la población no heterosexual frente a la heterosexual; dos, a partir de los prejuicios sexuales que son interiorizados por la población heterosexual; y tres, mediante el estigma interiorizado que conduce a las minorías sexuales a adoptar actitudes negativas frente a su propia persona y su grupo (Jaramillo y Restrepo, 2019: 98).

Por tanto, es indispensable considerar de manera general la sexualidad del adulto mayor en todos los procesos sociales, pero específicamente en 
el caso de las personas LGBT esta situación debe ser reconocida como un factor determinante de la identidad de esta población, ya que si no se reconocen sus orientaciones sexuales o identidades de género se invisibilizan sus realidades.

\section{Conclusiones}

Se constata que existe una desigualdad de género en cuanto al acceso a la educación entre los varones y las mujeres participantes en el estudio, mientras todos los varones gais entrevistados habían cursado como mínimo la formación técnica, y mayoritariamente tenían carreras profesionales o posgrados, las mujeres apenas habían concluido el bachillerato y no tenían otra formación. Esta situación también establece el hecho de que los varones tienen mayor acceso a una pensión frente a las mujeres. Lo que vendrá a determinar las condiciones de vida de las personas mayores LGBT, que en el caso de las mujeres lesbianas y transgénero se ven abocadas a la pobreza y la marginación.

En cuanto a las necesidades de las personas mayores LGBT, estas están vinculadas directamente con los estigmas y estereotipos que se identificaron a lo largo de la investigación, de manera general se puede decir que son considerados personas sin autonomía que al haber superado la edad productiva no tienen las mismas necesidades y derechos que los jóvenes y que, además, son catalogados como inactivos sexualmente. En este sentido, las personas mayores LGBT entrevistados manifiestan la necesidad de que sean incorporados a los programas destinados a su atención elementos relativos a la salud sexual y reproductiva que les permitan seguir envejeciendo con seguridad y dignidad, tal situación permitirá la visibilización de las personas diversas por orientación sexual e identidad de género dentro de este segmento de la población.

De otro lado, la idea de soledad y aislamiento a la cual están condenadas las personas LGBT mayores, no es del todo cierta, si bien algunos de los entrevistados viven solos, lo hacen por decisión propia y no por situaciones impuestas socialmente, esta decisión se toma pensado en la independencia personal para desarrollar su orientación sexual, la cual en algunas ocasiones debieron ocultar durante su juventud y adultez. Además, las condiciones socioeconómicas de estas personas, por lo menos de los gais, les aseguran una calidad de vida que les otorga independencia económica.

Por su parte, las personas mayores entrevistados han asumido su orientación sexual, algunos desde su adultez, y de manera general se puede decir que se han vinculado a los contextos LGBT en sus ciudades de residen- 
cia, unos solamente frecuentando los sitios de homosocialización, pero en otros casos como activistas de la población LGBT perteneciendo a asociaciones de este tipo, lo que les ha permitido aportar su tiempo libre en actividades para la reivindicación y el reconocimiento de los derechos de las personas sexualmente diversas. Sin embargo, en algunos casos el adulto mayor debe ocultar su orientación sexual, especialmente cuando requiere incorporarse al mercado laboral como única fuente de ingresos para asegurar su subsistencia en esta etapa de su vida, situación que genera tensiones entre dos aspectos fundamentales para el desarrollo personal, el empleo y la orientación sexual.

En todos los casos las familias conocen la orientación sexual o la identidad de género del adulto mayor y tienen una buena relación con este, cuando se les cuestiona sobre a quién recurrirá por ayuda en algún momento, de manera general mencionan a sus amigos, antes que, a la familia, y esto se puede deber al hecho que los amigos son el primer espacio de socialización y legitimación de su orientación sexual, donde las personas expresan libremente su orientación sexual y encuentran una red de apoyo. Por tanto, es evidente el papel que cumplen los amigos como red de apoyo emocional, material y cognitivo para las personas mayores LGBT, se debe trabajar sobre la consolidación y ampliación de esta red hacia la construcción de una red de apoyo institucional que reconozca las necesidades específicas del adulto mayor LGBT.

Finalmente, los entrevistados reconocen que existe una marginación y discriminación de las personas mayores en general, pero que esta se hace más fuerte en la población LGBT, ya que dentro de este se privilegia la juventud y la belleza, y además se mantienen los estereotipos sobre el envejecimiento, es decir, el hecho de considerar al adulto mayor LGBT como una persona asexuada que vive en el aislamiento y la soledad.

\section{REFERENCIAS BIBLIOGRÁFICAS}

Acuña, M., 2014, Discriminación social y estrategias de afrontamiento en los procesos de envejecimiento y la vejez de hombres homosexuales. Maestría en Derechos Humanos y Democracia, México: Facultad Latinoamericana de Ciencias Sociales.

Apoyo Positivo, 2019, ¿Cómo Es La Vejez Para Las Personas LGTB? Disponible en https://apoyopositivo.org/blog/apoyo-positivo/como-es-la-vejez-para-las-personas-lgtb/

Arango, V. y Ruiz, I., 2015, Diagnóstico de los adultos mayores en Colombia. Colombia: Fundación Saldarriaga Concha. Disponible en http://www.sdp.gov.co/ sites/default/files/diag_adul_mayor.pdf 
Bareiro, M., 2016, La exclusión de las personas trans del sistema educativo: un análisis de la experiencia en la educación de personas jóvenes y adultas en Paraguay. Buenos Aires: CLACSO. Disponible en http://biblioteca.clacso.edu.ar/clacso/becas/20160401010040/informefinaldeinvestigacionlaurabareiro.pdf

Bourdieu, P., 2003, El oficio de cientifico (Trad. J. Jordá). Barcelona: Anagrama.

Butler, J., 2004, Deshacer el género. Barcelona: Paidós.

Callejas, L., y Piña, C., 2005, "La estigmatización social como factor fundamental de la discriminación juvenil”, en El Cotidiano, 134, pp. 64-70. Disponible en https://www.redalyc.org/pdf/325/32513409.pdf

Cardona, D., Segura, Á., Garzón, M., Segura, A., y Cano, S., 2016, "Estado de salud del adulto mayor de Antioquia, Colombia", en Revista Brasileira de Geriatría e Gerontología, 1(19), pp. 71-86. DOI: http://dx.doi.org/10.1590/18099823.2016.14199

CEPAL, 2019, Personas mayores lesbianas, gais, bisexuales y transgénero (LGBT): derechos humanos y bienestar socioeconómico olvidados. Comisión Económica para América Latina y el Caribe (CEPAL). Disponible en https:// www.cepal.org/es/notas/personas-mayores-lesbianas-gais-bisexuales-transgenero-lgbt-derechos-humanos-bienestar

Colombia Diversa, 2020, Aunque intenten borrarnos. Informe de derechos humanos de personas LGBT en Colombia 2018. Bogotá. D.C: Colombia Diversa. Disponible en https://colombiadiversa.org/c-diversa/wp-content/uploads/2020/04/ publicaci\%C3\%B3n-7-_-Informe-de-violaciones-a-los-derechos-humanos-de-personas-LGBT-en-Colombia-en-2018.pdf

Comisión Interamericana de Derechos Humanos, 2015, Violencia contra Personas Lesbianas, Gay, Bisexuales, Trans e Intersex en América. Disponible en http:// www.oas.org/es/cidh/informes/pdfs/violenciapersonaslgbti.pdf

Consejería de Derechos Humanos de la Presidencia de la Republica de Colombia, 2017, Orientación sexual, identidad de género y derechos humanos isus derechos valen! Disponible en http://www.derechoshumanos.gov.co/observatorio/publicaciones/Documents/2017/170213-plegable-lgbti.-webpdf.pdf

García, M., 2015, Vejez y homosexualidad. Murcia: Universidad de Murcia-Departamento de sociología y trabajo social.

Gimeno, B., 2014, Vejez y orientación sexual. España. Madrid: Fundación 26 de diciembre. Disponible en http://www.fundacion26d.org/wp-content/ uploads/2014/06/informe-mayores-lgtb.pdf

Goffman, E., 2006, Estigma, la identidad deteriorada. Madrid: Amorrortu Editores.

Gracia, J., 2011, Los derechos humanos y la posición social de las personas mayores LGBT. Un supuesto especifico: los malos tratos. Madrid: Universidad Carlos III de Madrid-Instituto de Derechos Humanos Bartolomé de las Casas. 
Gros, A., 2016, "Judith Butler y Beatriz Preciado: una comparación de dos modelos teóricos de la construcción de la identidad de género en la teoría queer", en Civilizar, 16(30), pp. 245-260. Disponible en http://www.scielo.org.co/pdf/ccso/ v16n30/v16n30a18.pdf

Guasch, O., 1993, "Para una sociología de la sexualidad", en REIS: Revista española de investigaciones sociológicas, 64, pp. 105-122. Disponible en https:// dialnet.unirioja.es/servlet/articulo? codigo $=767350$

Help Age International, 2017, ¡Tenemos los mismos derechos! ¿Qué dicen las mujeres adultas mayores sobre su derecho a la no discriminación, a la igualdad, a vivir libres de violencia, abuso y negligencia en la vejez? Disponible en https:// social.un.org/ageing-working-group/documents/eighth/Entitledsamerights-Spanish.pdf

Huici, C., 1996, “Estereotipos”, en Morales J. F. y Huici, C., Psicología Social y Trabajo Social. Madrid: Mc Graw-Hill.

Iacub, R., 2015, Télam. Envejecimiento gay y trans, una realidad que necesita mayor visibilización y menos prejuicios. Disponible en https://www.telam.com.ar/ notas/201506/109899-vejez-gay-trans-diversidad.html

Jaramillo, J., y Restrepo, J., 2019, "Padres y madres homosexuales y bisexuales en Colombia. Experiencias de discriminación y estrategias de afrontamiento", en $R e$ vista Española de Sociología, 28(1), pp. 95-112. DOI: http://dx.doi.org/10.22325/ fes/res.2018.62

Kelly, J., 1977, “The aging male homosexual", in The Gerontologist, 4(17), pp. 328-332. DOI: https://doi.org/10.1093/geront/17.4.328

Lalive d'Epinay, C., Bickel, J., Cavalli, S., y Spini, D., 2011, El curso de la vida, emergencia de un paradigma interdisciplinario. Argentina: Encuentro Grupo Editor.

Ministerio de Protección Social, 2007, Política Nacional de Envejecimiento y Vejez. Bogotá, D.C. Disponible en https://www.minsalud.gov.co/Documentos\%20 y\%20Publicaciones/POL\%C3\%8DTICA\%20NACIONAL\%20DE\%20ENVEJECIMIENTO\%20Y\%20VEJEZ.pdf

Ministerio de Salud de Colombia, 1993, Resolución Número 008430, 1993, (4/10/1993). Disponible en https://urosario.edu.co/Escuela-Medicina/Investigacion/Documentos-de-interes/Files/resolucion_008430_1993.pdf

Ministerio de Salud y Protección Social, 2014, Política Colombiana de Envejecimiento Humano y Vejez. Bogotá, D.C. Disponible en [https://www.minsalud.gov. co/sites/rid/Lists/BibliotecaDigital/RIDE/DE/PS/POCEHV-2014-2024.pdf

Ministerio de Salud y Protección Social, 2019, Sala situacional de la Población Adulta Mayor. Bogotá, D.C. Disponible en https://www.minsalud.gov.co/proteccionsocial/Documents/Situacion\%20Actual\%20de\%201as\%20Personas\%20adultas\%20mayores.pdf 
Mujika, I., 2009, Guía para entender la realidad de Gais, lesbianas y transexuales mayores. País Vasco: ALDARTE, Centro de atención a gais, lesbianas y transexuales.

Rada, F., 2016, "Hay que desestigmatizar la vejez de las personas LGBT", en Diario Popular. Disponible en https://www.diariopopular.com.ar/sociedad/ hay-que-desestigmatizar-la-vejez-las-personas-lgbt-n267317

Rada, F., 2017, "La diversidad en el curso de la vida. Trayectorias y memorias de los y las mayores LGBT argentinos", in Henning, C. and Braz, C. (ed.), Género, sexualidade e curso da vida: Diálogos latino-americanos, Brasil: Editora Imprensa Univérsitaria, pp.111-143.

Revista Semana, 2017, "Ser adulto mayor en Colombia, todo un karma", en Revista Semana. Disponible en https:/www.semana.com/vida-moderna/articulo/calidad-de-vida-de-los-adultos-mayores-en-colombia-2017/527154

Rocha, T., 2009, "Desarrollo de la Identidad de Género desde una Perspectiva Psico-Socio-Cultural: Un Recorrido Conceptual", en Revista Interamericana de Psicología, 43(2), pp. 250.259. Disponible en http://pepsic.bvsalud.org/pdf/rip/ v43n2/v43n2a06.pdf

Sentido G., 2015, Envejecimiento LGBT, entre la falta de visibilización y los prejuicios. Disponible en http://www.sentidog.com/lat/2015/07/envejecimiento-lgbt-entre-la-falta-de-visibilizacion-y-los-prejuicios.html

Suárez, D., 2015, Situación de población adulta mayor LGBT en Costa Rica, El Salvador y Panamá. Centro de Investigación y Promoción para América Central de Derechos Humanos. Costa Rica: Centro de Investigación y Promoción para América Central de Derechos Humanos- CIPAC. Disponible en https://www.cipacdh.org/pdf/Informe_final_REGIONAL.pdf

Taylor, S., Bogdan, R., and Devault, M., 2000, Introduction to qualitative research methods: A guide and resource. New York: John Wiley y Sons.

Thumala, D., 2017, Cómo envejecemos: una mirada transdisciplinaria. Universidad Abierta De Chile. http://www.uabierta.uchile.cl/

Ulises, I., 2013, La transfobia en América Latina y el Caribe. Red LACTRANS. Disponible en http://redlactrans.org.ar/site/wp-content/uploads/2013/05/ La-Transfobia-en-America-Latina-y-el-Caribe.pdf

\section{RESUMEN CURRICULAR DE LOS AUTORES}

\section{Jair Eduardo Restrepo Pineda}

Magister en Cooperación al Desarrollo en la Especialidad de Movimientos Migratorios y Codesarrollo por la Universidad de Valencia, España y Doctor en Análisis y Evaluación de Procesos Políticos y Sociales por la Universidad Carlos III de Madrid, España, Docente e investigador del programa de Trabajo Social de la Corporación Universitaria Minuto de Dios UNIMINUTO. Hace parte del Grupo Interdisciplinario de Estudios Socia- 
les (GIES) avalado por la Corporación Universitaria Minuto de Dios UNIMINUTO y del Grupo de Investigación en Movilidad y Conflicto avalado por la Universidad Tecnológica de Pereira (UTP). Es reconocido como Investigador Asociado por el Ministerio de Ciencia, Tecnología e Innovación de Colombia. Entre sus publicaciones más importantes destacan: Percepción de líderes sociales y representantes de organizaciones públicas y privadas sobre la migración y los inmigrantes venezolanos en el municipio de Maicao (La Guajira, Colombia) (en coautoría con Juliana Jaramillo); De la invisibilidad al continuum de homofobia: Barreras socioculturales para las familias LGBTI en Colombia (en coautoría con Juliana Jaramillo Jarami1lo, Clara Patricia Pantoja Bohórquez, Karen Johanna Martínez Grisales); Padres y madres homosexuales y bisexuales en Colombia: aproximación a las percepciones sobre la familia.

Dirección electrónica: jair.restrepo@uniminuto.edu

Registro ORCID: https://orcid.org/0000-0002-3959-4550

\section{Andrea Carolina López Lorduy}

Trabajadora Social por la Corporación Universitaria Minuto de Dios UNIMINUTO, Sede Bello, pertenece al Semillero de Investigación en Familia, Género y Diversidad del programa de Trabajo Social de UNIMINUTO. Dirección electrónica: alopezlordu@uniminuto.edu.co

Registro ORCID: https://orcid.org/0000-0003-3528-3269

\section{Alejandro Arismendy Mejía}

Trabajador Social por la Corporación Universitaria Minuto de Dios UNIMINUTO, Sede Bello, pertenece al Semillero de Investigación en Familia, Género y Diversidad del programa de Trabajo Social de UNIMINUTO. Dirección electrónica: alexander2190@gmail.com Registro ORCID: https://orcid.org/0000-0002-0777-2383 